\title{
ИССЛЕДОВАНИЕ ОПЫТА УПРАВЛЕНИЯ ЗЕМЕЛЬНО-РЕСУРСНЫМ ПОТЕНЦИАЛОМ В РОССИИ И ЗА РУБЕЖОМ
}

\section{Мария Сергеевна Тараскина}

Сибирский государственный университет геосистем и технологий, 630108, Россия, г. Новосибирск, ул. Плахотного, 10, обучающийся, тел. (961)991-47-50, e-mail: mtaraskina99@mail.ru

\section{Наталья Олеговна Митрофанова}

Сибирский государственный университет геосистем и технологий, 630108, Россия, г. Новосибирск, ул. Плахотного, 10, кандидат технических наук, доцент кафедры кадастра и территориального планирования, тел. (923)137-18-88, e-mail: north-easter@yandex.ru

В настоящее время, практически, перед всеми странами мира возникает необходимость регулирования вопросов в области управления земельными ресурсами. Таким образом, исследование механизма системы управления землей, на сегодняшний день, является важным и актуальным, т.к. помимо экономической роли, система управления земельными ресурсами играет еще немаловажные социальные и правовые роли.

В представленной статье анализируются системы управления, информационное обеспечение и нормативно-правовые базы в России и за рубежом.

Сделаны выводы об эффективности системы управления земельными ресурсами в России.

Ключевые слова: управление земельными ресурсами, земельные отношения, земельные ресурсы, использование земельных ресурсов

\section{STUDY OF EXPERIENCE IN LAND RESOURCE POTENTIAL MANAGEMENT IN RUSSIA AND ABROAD}

\section{Maria S. Taraskina}

Siberian State University of Geosystems and Technologies, 10, Plakhotnogo St., Novosibirsk, 630108, Russia, Student, phone: (961)991-47-50, e-mail: mtaraskina99@mail.ru

\section{Natalia O. Mitrofanova}

Siberian State University of Geosystems and Technologies, 10, Plakhotnogo St., Novosibirsk, 630108, Russia, Ph. D., Associate Professor, Department of Cadastre and Territorial Planning, phone: (923)137-18-88, e-mail: north-easter@yandex.ru

At present, almost all countries of the world face the need to regulate issues in the field of land management.

The presented article analyzes the experience of managing land and resource potential abroad and in Russia, as well as evaluates the management and taxation systems, land relations.

Conclusions are made about the effectiveness of the land management system in Russia.

Keywords: land management, land relations, land resources, use of land resources

Земельные ресурсы - это важнейший элемент нашей жизни, основа экономического и социального благополучия страны. От их рационального использования зависит целостность государства, эффективность управления его территорией. 
Данное исследование посвящено рассмотрению систем управления земельными ресурсами в нескольких странах с целью выявления положительных и отрицательных моментов для предложения усовершенствования систему управления земельными ресурсами в Российской Федерации.

Российская Федерация. На сегодняшний день вся территория РФ поделена на семь категорий земель согласно их целевому назначению. Данная система сложилась более двух десятилетий назад и в основном опирается на опыт советского управления земельными ресурсами, что подразумевает под собой правовой режим их использования исходя, в первую очередь, из категории земель [2].

Система управления земельными ресурсами в Российской Федерации делится по вертикали (в виде уровней - рис. 1) и по горизонтали (в виде ветви рис. 2).

\section{Федеральный уровень}

Региональный уровень

Муниципальный уровень

Рис. 1. Уровни системы управления земельными ресурсами

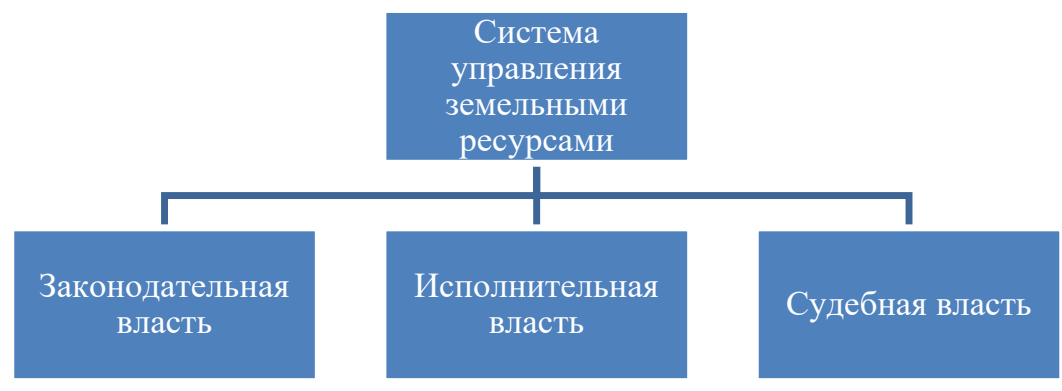

Рис. 2. Государственное регулирование системы управления земельными ресурсами

Система органов государственного управления земельными ресурсами образует единую управленческую вертикаль и находится во взаимодействии с государственными органами исполнительной власти: на федеральном уровне, уровне субъектов Федерации, муниципальных образований (административный район, поселения).

Представительными органами государственной власти являются аппарат Президента Российский Федерации, Совет Федерации и Государственная Дума Российской Федерации, а также соответствующие органы субъектов Российской Федерации [9]. 
Функциональная структура управления земельными ресурсами показана на рис. 3.

\section{Структура управления земельными ресурсами в РФ}

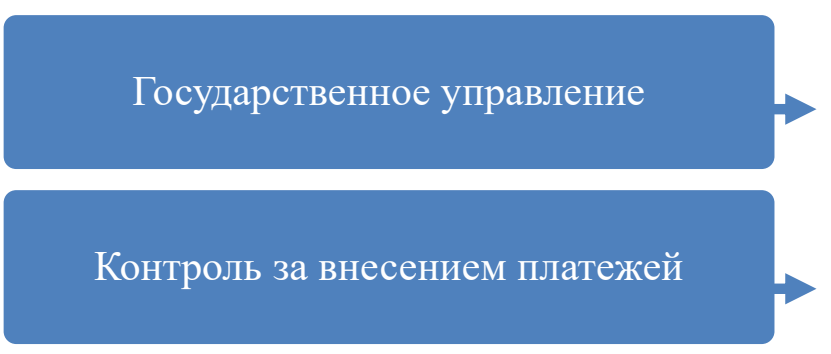

Надзор и контроль

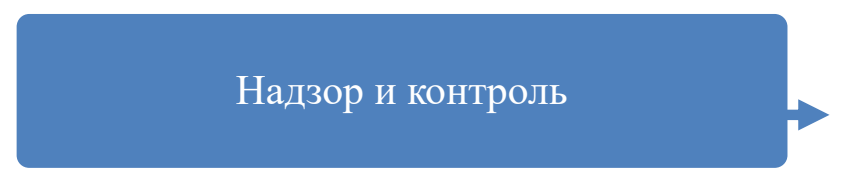

Владение, пользование и распоряжение земельными ресурсами

Земельные отношения осуществляется через территориальные органы, комитеты архитектуры и градостроительства, управления по мониторингу окружающей среды и т.П.

осуществляется через налоговые инспекции, территориальные органы Роснедвижимости и Т.П.

осуществляется через государственный земельный надзор (ГЗН) и муниципальный земельный контроль (МЗК), а также через природоохранные прокуратуры, органы экологической службы и др.

осуществляется через органы местного самоуправления

осуществляются через департаменты, комитеты , органы управления и т.п.

Рис. 3. Функциональная структура управления земельными ресурсами

Мероприятия по планированию рационального использования земельных ресурсов в Российской Федерации осуществляются ранее осуществлялось в генеральных схемах землеустройств, схемах использования и охраны земель [2]. На сегодняшний день эти данные документы заменили схемы территориального планирования, которые не предполагают изучение состояния земель и планирование их использования, что негативно сказывается на общем состоянии земельных ресурсов в нашей стране.

Информационное обеспечение в Российской Федерации производится благодаря таким системам:

- Единый государственный реестр недвижимости;

- система Росстата;

- информация, предоставляемая субъектами Российской Федерации в рамках запросов и в целях актуализации такой информации;

- Единая федеральная система о землях сельскохозяйственного назначения, созданная Минсельхозом России.

В настоящее время информационные системы имеют расхождения между собой, из-за чего наблюдается информационная недостаточность, которая необходима для управления земельными ресурсами. 
Одним из методов управления земельными ресурсами является: государственный земельный надзор (ГЗН) и муниципальный земельный контроль (МЗК), учёт и оценка земель, а также планирование эффективного использования земельно-ресурсного потенциала.

Несмотря на существующую систему управления земельными ресурсами, в Российской Федерации остаются нерешенными такие проблемы как:

- неполнота информационного обеспечения в области использования земельно-ресурсного потенциала и охраны земель;

- недостаточно продуманная система в области изменения и установления видов разрешённого использования земельных участков;

- недостаточно проработанное межведомственное взаимодействие между органами МЗК и ГНЗ;

- редко обновляющиеся картографические материалы для целей эффективного управления земельно-ресурсным потенциалом.

Основываясь на вышесказанном, следует отметить, что в системе управления земельными ресурсами в Российской Федерации остаются нерешенные актуальные вопросы, а значит, такая система нуждается в доработке и в постоянной «информационной поддержке».

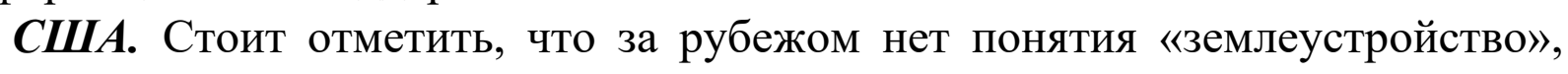
а есть близкие к нему:

- LandUsePlanning (в английском языке) - планирование использования земель (зонирование территорий);

- PhysicalPlanning (в английском языке) - территориальное планирование;

- LandManagement (в английском языке) - земельный менеджмент (реализация государственных, региональных, муниципальных программ по рациональному управлению землепользованием и развитию территорий);

- LandSurvey (в английском языке) - межевание, земельная съемка (кадастровые работы и картография);

- LandAdministration (в английском языке) - управление земельными ресурсами (имеется в виду иерархия власти);

- AmenagementFoncier (в французском языке) - близкое понятие к «землеустройству»;

- Flurbereinigung (в немецком языке) - также близкое понятие к «землеустройству».

Следует отметить, что в зарубежной практике понятие «кадастр» чаще всего связывают с понятием «недвижимость». А под недвижимостью при этом понимается следующее: это общественная опись, которая содержит данные по количеству, стоимости, собственности участков земли и прочего недвижимого имущества, прочно привязанного (связанного) к земле [4].

Система управления земельными ресурсами в США показана на рис. 4. 


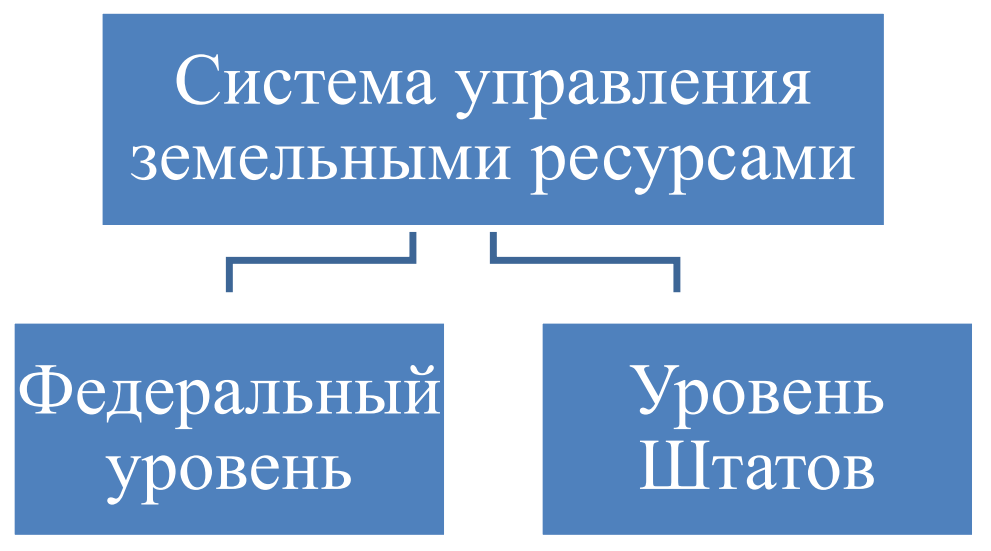

Рис. 4. Система управления земельными ресурсами в США

В Соединенных Штатах Америки в области управления земельным фондом не существует единого законодательства, поэтому каждый штат сам разрабатывает соответствующие документы, исходя из своей программы развития и организации территории. Необходимо заметить, что система землеустройства отличается высокой степенью децентрализованности и значительно отличается от штата к штату. Зонирование территории считается базой планирования использования территории.

Каждые пять лет в США проводится опись земель, стабильно производится обновление информации о почвах, эрозии и периодических землеустроительных обследованиях.

Права собственника в США бывают двух видов:

- право на использование поверхности земли;

- право на использование пространства под и над поверхностью земельного участка;

- право частной собственности на лесные насаждения (растущие на земельном участке собственника). Такое право может передаваться лесоизготовителю с целью вырубки.

Учет земель в США, в основном, осуществляется частными компаниями, собирающими информацию о стоимости земельных участков.

Кадастровый учет земельных участков, кадастровая съемка и ведение регистрационных архивов осуществляются через Бюро земельного управления.

Мониторинг земель осуществляется через Федеральное Агентство по защите окружающей среды. Армейский корпус инженеров Вооруженных Сил США занимается вопросами в таких областях:

- мелиорация и улучшение земель;

- водный контроль сельских районов в бассейнах рек, озёр и на прибрежных территориях.

Информационное обеспечение в сфере управления земельными ресурсами осуществляется с помощью базы данных (БД) ParcelPoint, которая функционирует с 2008 года. Также, в США сформирована специальная земельно- 
информационная система (ЗИС) «Единая государственная географическая информационная система», в которой хранятся количественные и качественные данные о состоянии земель.

Исходя из изученного материала, можно сказать, что существующая система управления земельно-ресурсным потенциалом в США является достаточно проработанной и эффективной.

Китай. Министерство земли и природных ресурсов является государственной системой управления, с помощью которого регулируются земельные отношения, и организуется землеустройство.

Функциями Министерства земли и природных ресурсов являются:

- оценка земли;

- управление земельными ресурсами;

- мониторинг земель;

- проведение земельных изысканий;

- развитие землепользования;

- землеустройство на сельскохозяйственных землях.

Важной особенностью является то, что в Китае право собственности на землю и право использования земли отделены друг от друга, а также объектом купли-продажи в рыночных отношениях в сфере землепользования является не право собственности, как, например, в России, а право пользования.

Свидетельства на право пользования выдают землеустроительные органы. Собственность на лесные земли или луга, право использовать лесные земли, луга, водную поверхность или приливные земли в целях ведения аквакультуры устанавливают в соответствии с законами о лесном хозяйстве, о лугах, о рыбном хозяйстве КНР. Предприятия или частные лица не имеют права самовольно захватывать землю или передавать ее посредством купли-продажи или иных методов, не предусмотренных законом [6].

В настоящее время, вся земля делится на:

- городские земли (принадлежат государству);

- сельские земли (принадлежат коллективным фермерским хозяйствам).

Государственный Совет распоряжается собственностью на государственные земли. Государство имеет право реквизировать землю у коллективов. Получается, что КНР присуще жесткое централизованное управление земельными ресурсами со стороны государства, которое организует национальную информационную сеть, земельный кадастр, мониторинг земель, ведет земельную статистику, финансирует землеустроительные мероприятия.

В настоящее время, в системе управления земельными ресурсами Китая, существует несколько основных проблем:

- низкий уровень экологической среды;

- опустынивание и эрозия почв;

- плохо исследованный запас существующих земельных ресурсов;

- низкий уровень управления землями сельскохозяйственного назначения. 
Таким образом, система управления земельно-ресурсным потенциалом в Китае также является недоработанной, в связи с этим необходимо провести её реформирование.

Франция. Уровни власти Франции показаны на рис. 5.

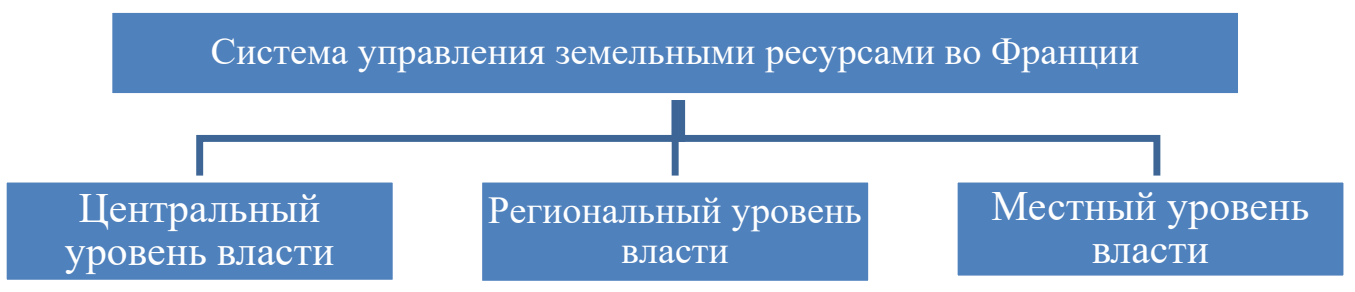

Рис. 5. Уровни власти Франции

Власти Франции регулируют оборот купли-продажи земельных участков для предотвращения спекуляций. Министерство снабжения транспорта и жилья осуществляет земельную политику, но также и существуют специальные компании, занимающиеся разработкой различных мероприятий по организации рационального использования земельных ресурсов во Франции.

Под частной собственностью здесь понимают принадлежность земли на праве собственности частным лицам и обществам.

Устройство территорий считается базой планирования использования территории.

Основным нормативно-правовым документом, который регулирует земельно-имущественные отношения, является Гражданский кодекс Франции 1804 года (Кодекс Наполеона Бонапарта) [3].

В кадастре содержатся сведения об изменениях физического, экономического и юридического характера. Система кадастра во Франции показано на рис. 6.

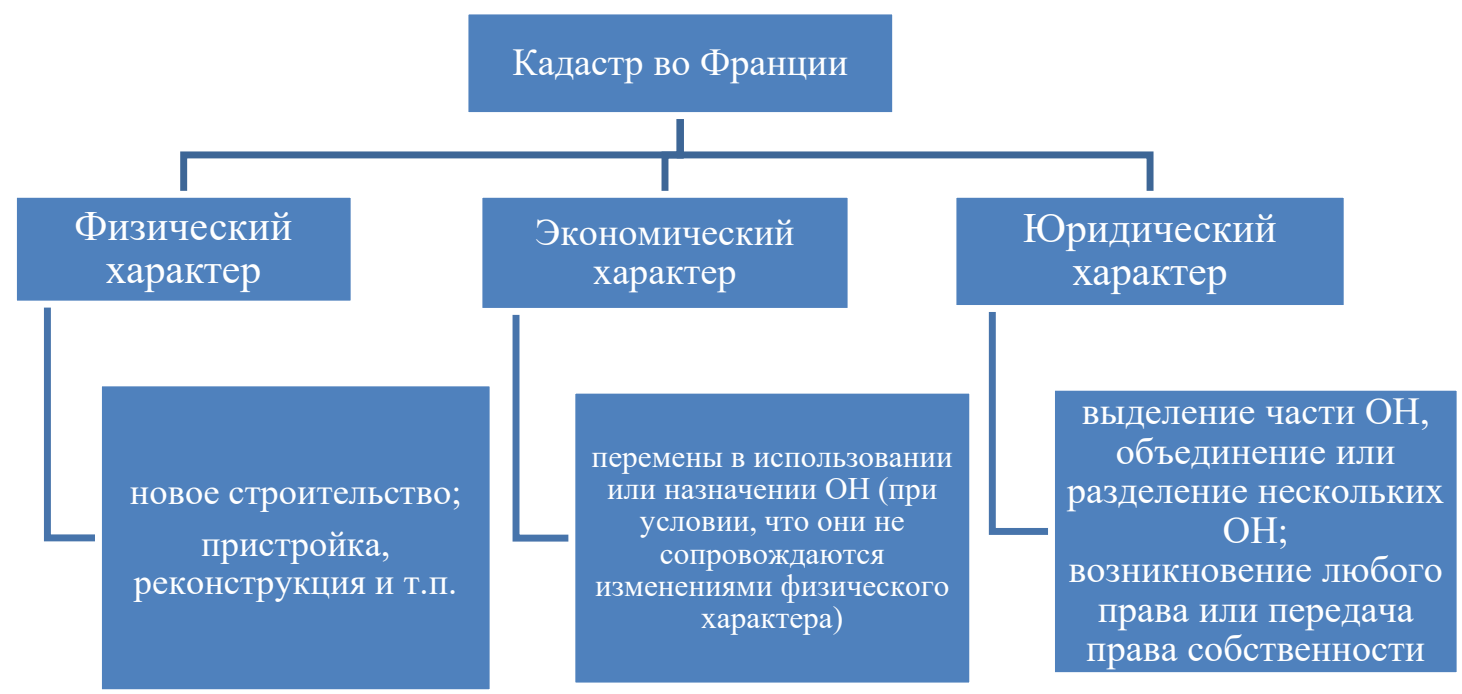

Рис. 6. Система кадастра во Франции 
Для ведения земельно-кадастровых работ в стране действует Генеральная дирекция налоговых служб, налоговых и земельных операций (Direction General des Import Services des Operations Fiscales et Fonciers), расположенная в Париже, а в каждом департаменте имеются отдельные дирекции налоговых служб. Их подразделениями являются налоговые центры, кадастровые инспекции, земельные отделы, службы налогообложения, существуют также региональные земельно-кадастровые информационные центры [1].

Во Франции система мониторинга земель функционирует на двух уровнях, которые показаны на рис. 7.

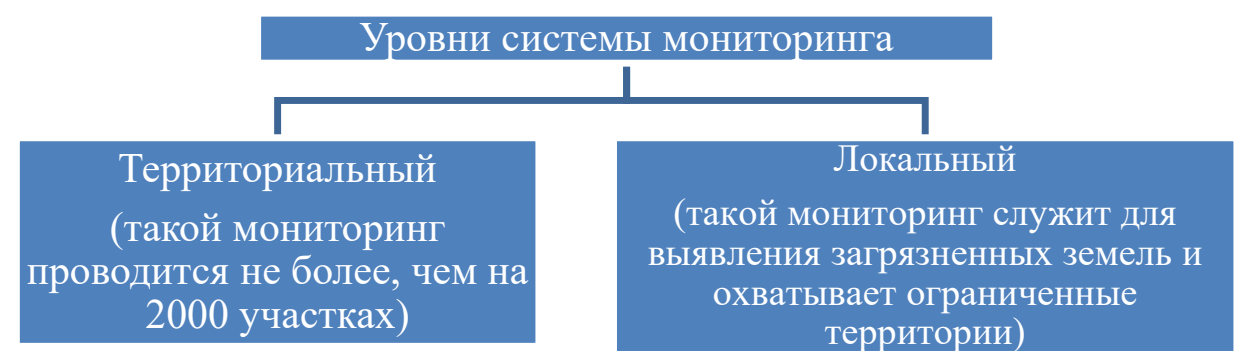

Рис.7. Уровни системы мониторинга земель во Франции

Информационными системами в сфере управления земельными ресурсами во Франции являются:

- PCI Vecteur;

- PCI Image.

Подводя итог, можно сказать, что во Франции, каждый муниципалитет и каждый городской департамент строит свой порядок управления недвижимостью, владеет и распоряжается своей собственностью. Хотя такая система и приводила к частым случаям коррупции, она считается достаточно эффективной [5].

Изучив системы управления земельными ресурсами в нескольких странах, можно сказать, что для того, чтобы реформировать систему управления земельными ресурсами в Российской Федерации, нужны следующие изменения:

- в полном объеме изучить содержание и правовое обеспечение землеустройства, как одной из важных функций организации земельных пространств;

- создание современной системы кадрового и научного обеспечения системы управления земельными ресурсами;

- принятие мер по повышению квалификации специалистов органов местного самоуправления, осуществляющих мероприятия по муниципальному земельному контролю;

- сформировать единый орган, обладающий всей полнотой функций и ответственности за рациональное использование и охрану земельных ресурсов. 


\section{БИБЛИОГРАФИЧЕСКИЙ СПИСОК}

1. Анализ современных кадастровых систем. [Электронный ресурс] - Режим доступа:http://masters.donntu.org/2010/igg/vinichenko/library/article6.htm.

2. Власенко Т.В., Симонова А.А. Проблема использования земель г. Ростова-на-Дону не по целевому назначению // Экономика и экология территориальных образований: научнопрактический журнал. Ростов н/Д: РГСУ. - 2015. - № 3. - С.25-28.

3. Волков С.Н. Землеустройство. Т. 7. Землеустройство за рубежом - М.: КолосС, 2005. $-408 \mathrm{c}$.

4. Интернет ресурс «Студенческая энциклопедия». [Электронный ресурс] - Режим доступа: https://studopedia.ru/5_105651_harakteristika-i-znachenie-informatsii-dlya-uzr.html (Управление земельными ресурсами : учеб. пособие / Н. В. Гагаринова, М. В. Сидоренко. 2-е изд. - Краснодар : КубГАУ, 2017. - 160 с.

5. Проблемы регулирования рынка городских земель в России. [Электронный реcypc]http://www.m-economy.ru/art.php?nArtId=2516.

6. Руденко И.В., Вараксин Г.С.Особенности планирования землепользования за рубежом. Ж. «Вестник КрасГАУ» 2015, №5, раздел «Лесное хозяйство».

7. Системы информационного обеспечения управления земельными ресурсами в зарубежных странах и в России. [Электронный pecypc] - Режим доступа: https://eintegral.ru/rubriki/nauchnyie-konferentsii/integral-22-2020-37.

8. Управление земельными ресурсами : учеб. пособие / Н. В. Гагаринова, М. В. Сидоренко. - 2-е изд. - Краснодар : КубГАУ, 2017. - 160 с.

9. Эффективность системы ГЗК [Текст]: лекция - А.А. Рассказова 2013.

(C) М. С. Тараскина, Н. О. Митрофанова, 2021 